\title{
Anniversary Editorial: One year of Cardiovascular Ultrasound Eugenio Picano*
}

\author{
Address: CNR, Institute of Clinical Physiology, Pisa, Italy \\ Email: Eugenio Picano* - picano@ifc.cnr.it \\ ${ }^{*}$ Corresponding author
}

Published: 03 March 2004

Cardiovascular Ultrasound 2004, 2:3
Received: 24 February 2004

Accepted: 03 March 2004

This article is available from: http://www.cardiovascularultrasound.com/content/2/1/3

(c) 2004 Picano; licensee BioMed Central Ltd. This is an Open Access article: verbatim copying and redistribution of this article are permitted in all media for any purpose, provided this notice is preserved along with the article's original URL.

Cardiovascular Ultrasound celebrates its first birthday: a good occasion to review the last year's activity, to present the journal to the reader, to thank the many who contributed to the good start, and to design the near future of the journal.

\section{What is Cardiovascular Ultrasound?}

Cardiovascular Ultrasound is an Open Access, peerreviewed online journal covering clinical, technological, experimental, biological, and molecular aspects of ultrasound applications in cardiovascular physiology and disease.

Cardiovascular Ultrasound is aimed at providing a suitable tribune for the most current, clinically and biologically relevant, and high quality research in the field of ultrasound of heart and vessels. The journal publishes peerreviewed original research, updated reviews, case reports on challenging and/or unusual diagnostic aspects, and expert opinions on new techniques and technologies. Other feature of interest to the cardiologist, the sonographer and allied scientists is the "natural born digital" nature of the journal, with the possibility to publish colour illustrations and video clips with no extra costs. This feature is especially attractive in a field so dynamic (both in a conceptual and in a cinematic sense) as ultrasound. The possibility to go immediately to Pubmed, and the publication of video-clips, will tremendously increase the scientific impact of your material. Cardiovascular Ultrasound might become a good first choice for much of your "hot material", when time is not an independent variable.

The cardiovascular ultrasound community needs an Open Access forum in which to publish peer-reviewed articles with speed (in revision and publication), and versatility (in arguments, ranging from biology to engineering to clinical echocardiography). Cardiovascular Ultrasound aims to be that forum.

\section{Peer review policies}

Manuscripts must be submitted to Cardiovascular Ultrasound electronically using the online submission system. Full details of how to submit a manuscript are given in the instructions for authors. Cardiovascular Ultrasound reviews all the material it receives. About $10 \%$ of articles are rejected after review in-house. The usual reasons for rejection at this stage are insufficient originality or serious scientific flaws. We aim to reach a decision on such papers within 3 days. The remaining articles are sent to two external reviewers. Reviewers advise the editor, who is responsible for the final decision to accept or reject the manuscript. In the first year of editorial life, the acceptance rate of the journal has been $79 \%$, with time from submission to primary decision $<10$ days. A total of 24 articles were submitted, and 19 have been published.

\section{General journal policies}

Cardiovascular Ultrasound is published by BioMed Central, an independent publisher committed to ensuring peerreviewed biomedical research is Open Access. That means it is freely and universally accessible online, it is archived in at least one internationally recognised free access repository, and its authors retain copyright, allowing anyone to reproduce or disseminate articles, according to the BioMed Central copyright and licence agreement. Cardiovascular Ultrasound however, has taken this further, by making all its content Open Access.

Cardiovascular Ultrasound's Open Access policy changes the way in which articles are published. Firstly, all articles 
become freely and universally accessible online, and so an author's work can be read by anyone at no cost. Secondly, the authors hold copyright for their work and grant anyone the right to reproduce and disseminate the article, provided that it is correctly cited and no errors are introduced [1]. Thirdly, a copy of the full text of each Open Access article is permanently archived in an online repository separate from the journal. Cardiovascular Ultrasound's articles are archived in PubMed Central [2], the US National Library of Medicine's full-text repository of life science literature, and also in repositories at the University of Potsdam [3] in Germany, at INIST [4] in France and in e-Depot [5], the National Library of the Netherlands' digital archive of all electronic publications.

\section{Benefits of Cardiovascular Ultrasound's Open Access policy}

Open Access has four broad benefits for science and the general public. Firstly, authors are assured that their work is disseminated to the widest possible audience, given that there are no barriers to access their work. This is accentuated by the authors being free to reproduce and distribute their work, for example, by placing it on their institution's website. It has been suggested that free online articles are more highly cited because of their easier availability [6]. Secondly, the information available to researchers will not be limited by their library's budget, and the widespread availability of articles will enhance literature searching [7]. Thirdly, the results of publicly funded research will be accessible to all taxpayers and not just to those with access to a library with a subscription. As such, Open Access could help to increase public interest in, and support of, research. Note that this public accessibility may become a legal requirement in the USA if the proposed Public Access to Science Act is made law [8]. Fourthly, a country's economy will not influence its scientists' ability to access articles because resource-poor countries (and institutions) will be able to read the same material as wealthier ones (although creating access to the internet is another matter [9]).

\section{Cardiovascular Ultrasound celebrates its first birthday: and the winner is}

The electronic nature of the journal makes it easy to monitor the level of interest of the journal and of the individual articles. In our special hit-parade, the top three most frequently accessed articles, have been:

\section{Number 3 - Bronze medal}

[10] Djordjevic-Dikic A, Ostojic M, Beleslin B, Nedeljkovic I, Stepanovic J, Stojkovic S, Petrasinovic Z, Nedeljkovic M, Saponjski J, Giga V. Low-dose adenosine stress echocardiography: Detection of myocardial viability. Cardiovasc Ultrasound. 2003, 1:7

\section{Number 2 - Silver medal}

[11] Kumar V Ramnarine, Tim Hartshorne, Yvonne Sensier, May Naylor, Joanne Walker, A Ross Naylor, Ronney B Panerai, David H Evans. Tissue Doppler imaging of carotid plaque wall motion: a pilot study. Cardiovascular Ultrasound 2003, 1:17

\section{Number I - Gold medal}

[12] Marek Krzanowski, Wojciech Bodzoń, Paweł Petkow Dimitrow. Imaging of all three coronary arteries by artery transthoracic echocardiography. An illustrated guide.Cardiovascular Ultrasound 2003, 1:16

These three articles summarize the strengths of the journal: the possibility to have state-of-the art reviews (with abundant images and clips, of heart breaking colorful beauty), epitomized by our gold medal; the possibility to present novel technical notes on cutting edge aspects of clinical applications of US (the silver medal), and the possibility to have strong and original, high quality research published and included in PubMed 15 days aftersubmission (the bronze medal).

The geographic origin of the articles is also interesting. Articles were submitted from 4 continents and 13 different countries, again mirroring the international melting pot that generates the journal.

A special thank you to the reviewers who met the challenge to provide informed and timely information within the "impossible" 7 day deadline: as a token of appreciation, some of them now enter the Editorial Board.

This Editorial Board will be renewed and refreshed every year.

\section{Cardiovascular Ultrasound: the second year}

After the first year, the Journal grows. Fresh blood has been injected into the Editorial Board, adding leading experts representative of the full cultural and geographic spectrum of the Cardiovascular Ultrasound expertise. The journal has been also formally endorsed and recommended by a Scientific society, the European Society for Noninvasive Cardiovascular Dynamics. The journal welcomes any kind of cooperation with existing societies that recognize in CU a suitable publishing medium for their members. The links will be smoother with a human liaison between the society and the journal, identified this year by Dr Cesare Rusconi for the European Society for Cardiovascular Dynamics and by Dr Jorge Lowenstein for EcoInterAmericano Society. The endorsement by other societies might follow in the future.

After the first year, we decided to take even more advantage of the interactive nature of the journal. Therefore Edi- 
torials, Commentaries, and Reviews will be more present. Next year the journal will make a serious attempt to disseminate and debate the knowledge of the social, economic, biological, medical and legal implications of our imaging acts. Cardiovascular Ultrasound encourages any scientific and editorial effort promoting the sustainability of medical imaging [13].

\section{Conclusion: Cardiovascular Ultrasound, a good option for your ideas}

If time is not important for your research; if you feel satisfied with your black-and-white still frame images and you are happy to pay exorbitant publishing costs for one color figure, do not think of Cardiovascular Ultrasound.

But if you have something to say, and you want to lose little of your time although you are willing to undergo a strict quality control of your research through a selective, rigorous peer-review system, this can be your journal.

\section{Competing interests}

There are no financial competing interests in relation to my work on behalf of the journal. All secretarial resources are supplied by Institutional funding from National Research Council and from the clinical activity of the Echocardiographic lab of the Institute of Clinical Physiology in Pisa.

\section{References}

I. BioMed Central Open Access Charter [http://www.biomedcen tral.com/info/about/charter]

2. PubMed [http://www.pubmedcentral.org]

3. Potsdam [http://www.uni-potsdam.de/over/homegd.htm]

4. INIST [http://www.inist.fr/index en.php]

5. e-Depot [http://www.kb.nl/]

6. Lawrence S: Free online availability substantially increases a paper's impact. Nature 200I, 4I I:52 I.

7. Velterop J: Should scholarly societies embrace Open Access (or is it the kiss of death)? Learned Publishing 2003, 16:167-169.

8. Open Access law introduced [http://www.biomedcentral.com/ news/20030627/04]

9. Tan-Torres Edejer T: Disseminating health information in developing countries: the role of the internet. BMJ 2000, 321:797-800.

10. Djordjevic-Dikic A, Ostojic M, Beleslin B, Nedeljkovic I, Stepanovic J, Stojkovic S, Petrasinovic Z, Nedeljkovic M, Saponjski J, Giga V: Lowdose adenosine stress echocardiography: Detection of myocardial viability. Cardiovasc Ultrasound 2003, I:7.

II. Ramnarine KV, Hartshorne T, Sensier Y et al.: Tissue Doppler imaging of carotid plaque wall motion: a pilot study. Cardiovascular Ultrasound 2003, I:17.

12. Krzanowski M, Bodzoń W, Dimitrow PP: Imaging of all three coronary arteries by artery transthoracic echocardiography. An illustrated guide. Cardiovascular Ultrasound 2003, I:16.

13. Picano E: Sustainability of medical imaging. BMJ 2004, 328:578-580.
Publish with Bio Med Central and every scientist can read your work free of charge

"BioMed Central will be the most significant development for disseminating the results of biomedical research in our lifetime. "

Sir Paul Nurse, Cancer Research UK

Your research papers will be:

- available free of charge to the entire biomedical community

- peer reviewed and published immediately upon acceptance

- cited in PubMed and archived on PubMed Central

- yours - you keep the copyright

Submit your manuscript here:

http://www.biomedcentral.com/info/publishing_adv.asp
BioMedcentral 